\title{
Absence of effect of dipyridamole on renal and platelet function in diabetes mellitus
}

\author{
D M Gibb, D Dunger, M Levin, D Grant, P Jones, T M Barratt
}

\begin{abstract}
We evaluated the effect of dipyridamole $(5 \mathrm{mg} / \mathrm{kg} / \mathrm{day})$ for $12 \mathrm{months}$ on renal and platelet function in 53 children with insulin dependent diabetes mellitus (IDDM) in a prospective double blind placebo controlled trial. Urine albumin excretion (expressed as the geometric mean albumin to creatinine concentration ratio (UA/UC) was measured every three months throughout the study. At 12 months, the geometric mean UA/UC was no different in diabetic children receiving dipyridamole, $0.60 \mathrm{mg} / \mathrm{mmol}$, when compared with those receiving placebo, $0.87 \mathrm{mg} / \mathrm{mmol}$. Glomerular filtration rate, urinary excretion of retinol binding protein, and $\mathrm{N}$-acetyl- $\beta$-Dglucosamidase (NAG), blood pressure, and spontaneous platelet aggregation in response to stirring whole blood did not differ between the two groups at 12 months. Subgroup analysis to include only those children with high UA/UC before entry into the study also failed to show an effect of the drug on UA/UC.

Eleven children had either persistently high UA/UC ( $n=8$ : four on dipyridamole, four on placebo) or progression to high UA/UC $(n=3$ : two on dipyridamole, one on placebo). These children had significantly higher urinary excretion of retinol binding protein and NAG, bigger kidneys, and higher diastolic blood pressure both before and after treatment than the remaining 42 children, whereas there was no difference in spontaneous platelet aggregation between the two groups. These observations on the associations between UA/UC and other paremeters of renal function suggest that measurement of 'tubular' proteins and diastolic blood pressure as well as UA/UC may contribute to the identification of those at risk of developing nephropathy.
\end{abstract}

Paediatric Nephrology, Institute of Child Health,

London

D M Gibb

$M$ Levin

T M Barratt

Endocrine Department,

Hospitals for

Sick Children,

London

D Dunger

D Grant

Boehringer Ingelheim, Bracknell

P Jones

Correspondence to:

Dr D M Gibb

Department of Immunology and Infectious Diseases, Institute of Child Health 30 Guilford Street, London WCIN IÉH.

Accepted 1 August 1989

It has been suggested that platelet activation contributes to the pathogenesis of both the macrovascular and the microvascular complications of diabetes mellitus. ${ }^{1-3}$ Shortened platelet survival, ${ }^{4}$ increased platelet aggregation in vitro, ${ }^{5}$ and release of intraplatelet substances ${ }^{56}$ have all been reported in adults with established microvascular complications. In those without complications the studies have been conflicting, however, with some $^{78}$ but not others ${ }^{-11}$ reporting abnormalities of platelet function. Futher evidence linking platelet activation with diabetic nephropathy comes from a study using the specific inhibitor of thromboxane synthetase, UK-38,485, in which 30 patients with microalbuminuria had significantly reduced urine albumin excretion rates after 16 weeks of treatment with this drug compared with placebo, and albumin rebounded to pretreatment concentrations after its discontinuation. ${ }^{12}$

Dipyridamole, a commonly prescribed antiplatelet drug used in combination with aspirin as an antithrombotic agent, ${ }^{13} 14$ has been reported to reduce urine albumin excretion and to increase platelet survival in different glomerulopathies in both adults and children. ${ }^{15} 16$ In combination with aspirin, it has also been reported to decrease urine albumin excretion in studies of adults with established diabetic nephropathy. ${ }^{17-20}$ Although it has been proposed that this effect is mediated by a change in platelet function, there is also experimental evidence suggesting that it may reduce proteinuria by causing efferent arteriolar dilatation, with a resulting decrease in hyperfiltration. ${ }^{21} 22$

The studies undertaken so far have been in patients with established or incipient nephropathy and it is unknown whether these drugs may be effective in the primary prevention of nephropathy. In a previously reported cross sectional study of children and adolescents with insulin dependent diabetes mellitus (IDDM), we observed a small but significant increase in platelet aggregation in whole blood in vitro compared with normal children. We also observed increases in both urine albumin excretion and glomerular filtration rate and noted a threshold association between the two, those children with high urine albumin excretion also having a high glomerular filtration rate and larger than average kidneys. ${ }^{23}$ We now report the results of a placebo controlled trial of the effect of dipyridamole taken for 12 months on renal and platelet function in these same children with IDDM. In addition, over this time period, we investigated the evolution of the association between renal and platelet function.

\section{Subjects and methods}

SUBJECTS

Sixty children with IDDM were recruited from the diabetic clinics of the Hospitals for Sick Children, London. Their mean (SD) age was $13.1(3.5)$ years and the mean (SD) duration of diabetes was $7 \cdot 0(4 \cdot 3)$ years; there were 33 girls and 27 boys. Two children were receiving anticonvulsant drugs (carbamazepine and sodium valproate); the remainder were receiving no other treatment except insulin and had no significant disease other than diabetes. None of the children had taken aspirin during the two weeks before entry into the trial and all were given oral and written instructions to avoid taking aspirin 
like drugs throughout the trial period. No child had evidence of urinary tract infection or renal abnormality on ultrasound at entry into the study.

\section{TRIAL DESIGN}

The trial was a double blind placebo controlled study with the randomisation stratified for urine albumin excretion. The primary end point was to ascertain whether dipyridamole modified urine albumin excretion in childhood diabetes. Secondary endpoints were to observe whether there was any effect of the drug on platelet function and other indices of renal function.

We wished to detect a $30 \%$ difference between treatment and placebo groups at 12 months, assuming a standard deviation of $35 \%$. To give $80 \%$ power at the $95 \%$ level of significance 20 patients per group were required.

Urine albumin excretion was measured within the three months before, and again at entry to the trial. In addition, urinary excretion of retinol binding protein, $\mathrm{N}$-acteyl- $\beta$-D glucosaminidase (NAG), renal size, blood pressure, glycated haemoglobin $\left(\mathrm{HbA}_{\mathrm{lc}}\right)$, and platelet aggregation were measured in all children at entry to the trial. Measurements of glomerular filtration rate were available on 41 children only. The children were then randomly allocated to receive either dipyridamole, $5 \mathrm{mg}$ / $\mathrm{kg}$ body weight/day, or matching placebo in a twice daily dosage. Unmarked preparations were provided by Boehringer Ingelheim and the randomisation schedule was kept in the hospital pharmacy. All children were followed up by the same investigator and neither she nor the patients were aware of the treatment each child was receiving.

Measurements of blood pressure, pubertal state, urine albumin excretion, 'spontaneous' platelet aggregation, and $\mathrm{HbA}_{\mathrm{lc}}$ were made at intervals of three months. In addition, renal size and tubular proteins were measured at completion of the study at 12 months, and glomerular filtration rate was remeasured in the 41 children initially studied. Final estimations of blood pressure, $\mathrm{HbA}_{1 \mathrm{c}}$, urine albumin excretion, and platelet aggregation were undertaken three months after discontinuing the drug.

The study had the approval of the ethics committee of the Hospital for Sick Children, Great Ormond Street, London.

\section{ANALYTICAL METHODS}

Urinary albumin (UA) was measured by radioimmunoassay using a commercial kit (Diagnostic Products (UK) Ltd, sensitivity 0.5 $\mathrm{mg} / \mathrm{l}$, intra-assay and interassay variability $4 \%$ and $5 \%$ respectively). Urinary retinol binding protein (URBP) was measured by an enzyme linked immunosorbent assay (ELISA) technique using rabbit antisera (Dako Ltd). ${ }^{24}$ Urinary NAG (UNAG) was measured by an automated colorimetric method using p-nitrophenyl-Nacetyl- $\beta$-D-glucosamide (Sigma Chemical Co) as substrate. ${ }^{25}$ Urine creatinine (UC) was measured by the Jaffé reaction. Urinary excretion of protein was expressed as the geometric mean of the ratio of the protein concentration to that of creatinine in two consecutive overnight urine samples (UA/UC $(\mathrm{mg} / \mathrm{mmol}), \mathrm{URBP} / \mathrm{UC}$ $(\mu \mathrm{g} / \mathrm{mmol}), \quad \mathrm{UNAG} / \mathrm{UC}$ ( $\mu \mathrm{mol}$ p-nitrophenyl (pnp) hour $/ \mathrm{mmol})$ ). The upper limit of normal was defined as the upper $95 \%$ tolerance limit in 45 normal children calculated from log data. This was $1.17 \mathrm{mg} / \mathrm{mmol}$ for UA/UC, $15.0 \mu \mathrm{g} /$ $\mathrm{mmol}$ for URBP/UC, and $25.0 \mu \mathrm{mol}$ pnp hour/ mmol for UNAG/UC. ${ }^{26}$ We have previously shown that a UA/UC value of $1.17 \mathrm{mg} / \mathrm{mmol}$ is equivalent to a urine albumin excretion rate of $8 \cdot 2 \mu \mathrm{g} / \mathrm{min} / 1 \cdot 73 \mathrm{~m}^{2}$ surface area. ${ }^{27}$

Glomerular filtration rate was measured during a constant infusion of 51-chromium edetic acid ( ${ }^{51} \mathrm{Cr}$-EDTA) under conditions of water diuresis by standard renal clearance techniques with spontaneous voiding of urine. The upper $95 \%$ tolerance limit in 15 adult controls was $135 \mathrm{ml} / \mathrm{min} / 1 \cdot 73 \mathrm{~m}^{2}$ surface area. ${ }^{23}$

Renal length was measured by ultrasonography with the child in the prone position and was related to normal data for right and left kidney lengths plotted against body height. ${ }^{28}$ The standard deviation (SD) score for each kidney was calculated from the formula: SD score $=$ (measurement-mean)/SD. Data on the diabetic children was expressed as the mean of the right and left kidney length SD scores, compared with these normal published sonographic growth charts. ${ }^{28}$

Blood pressure was measured using a random zero sphygmomanometer with the child seated. Results are presented both as raw data and SD scores calculated from the American Task Force Data for blood pressure in normal children. ${ }^{29}$

$\mathrm{HbA}_{1 \mathrm{c}}$ was measured by electrophoresis (normal range 5-8\%).

Platelet aggregation was measured in whole blood in response to stirring using the Ultraflo 100 whole blood platelet counter. ${ }^{30} \mathrm{~A}$ sample of $5 \mathrm{ml}$ blood was taken into a polypropylene syringe using a 19 gauge needle and immediately transferred into a polystyrene tube containing $0.5 \mathrm{ml} 3.8 \%$ trisodium citrate dihydrate. A $0.5 \mathrm{ml}$ aliquot was then stirred in a plastic tube at $1000 \mathrm{rpm}$ at $37^{\circ} \mathrm{C}$. A $20 \mu$ l aliquot was taken two minutes after stirring had started, and immediately fixed with $40 \mu \mathrm{l}$ of formalinedetic acid solution to prevent further aggregation or disaggregation before counting. All samples were counted in tripicate and the mean taken. Aggregation was expressed as the percentage fall in platelet count at two minutes compared with the count in an aliquot taken immediately before stirring. ${ }^{30}$ All experiments were performed between one and three hours after venepuncture as, in agreement with Saniabadi et al, we have found that aggregation after venepuncture increases over the first hour and then stabilises. ${ }^{31}$ The upper $95 \%$ tolerance limit for spontaneous aggregation in 26 normal children was $27 \%$ at two minutes. ${ }^{23}$ Aggregation in response to platelet activating factor was also measured at the three month visit. After one minute stirring, $4 \mu \mathrm{l}$ of $500 \mathrm{nM}$ platelet activating factor was added to $500 \mu \mathrm{l}$ whole blood (making a final concentration of $4 \mathrm{nM}$ platelet activating factor) and aliquots taken as described above at 15 seconds, 30 seconds, one minute and two minutes later. 
STATISTICAL METHODS

Withdrawals from the study were excluded from the analysis; all occurred in the first three to six months.

Before analysis, it was decided that the following covariates should be considered: baseline values, age, Tanner puberty stage in three groups (stage 1, stages 2 and 3, stages 4 and 5), duration of diabetes, and sex. Age and duration of diabetes were particularly important because the children treated with dipyridamole were on average 1.7 years older and had a disease duration of 2.6 years longer than those treated with placebo.

All covariates were tested with the primary and secondary end points; only age and baseline values indicated a consistent effect and hence only these were included in the final model.

Analysis of variance tests were used at each visit, but significance was only attached to the 12 months result. In cases where UA/UC data $(n=5)$ or platelet aggregation data $(n=4)$ at 12 months were missing, the previous recorded reading at nine months was used. UA/UC, $\mathrm{URBP} / \mathrm{UC}$, and UNAG/UC were log transformed before analysis; all tests indicated that the data (transformed as appropriate) did not deviate appreciably from normality.

\section{Results}

WITHDRAWALS AND SIDE EFFECTS

Seven children withdrew from the study (four defaulted and three developed headaches: two on dipyridamole and one on placebo). Ten others reported mild headaches (four on dipyridamole and six on placebo); a temporary reduction in dose followed by a gradual increase back to $5 \mathrm{mg} / \mathrm{kg}$ /day alleviated headaches in these children regardless of treatment.

\section{BASELINE DATA}

Excluding withdrawals, the 28 children in the placebo group were younger and had a shorter duration of diabetes than the 25 children taking dipyridamole (table 1). The results of UA/UC, tubular protein excretion, blood pressure, $\mathrm{HbA}_{1 \mathrm{c}}$, glomerular filtration rate, and platelet aggregation at baseline were similar in both groups.

\section{URINE ALBUMIN EXCRETION}

There was no evidence of treatment differences over the 15 months. During the first nine months, the placebo group had slightly lower UA/UC, but at 12 months this was reversed and

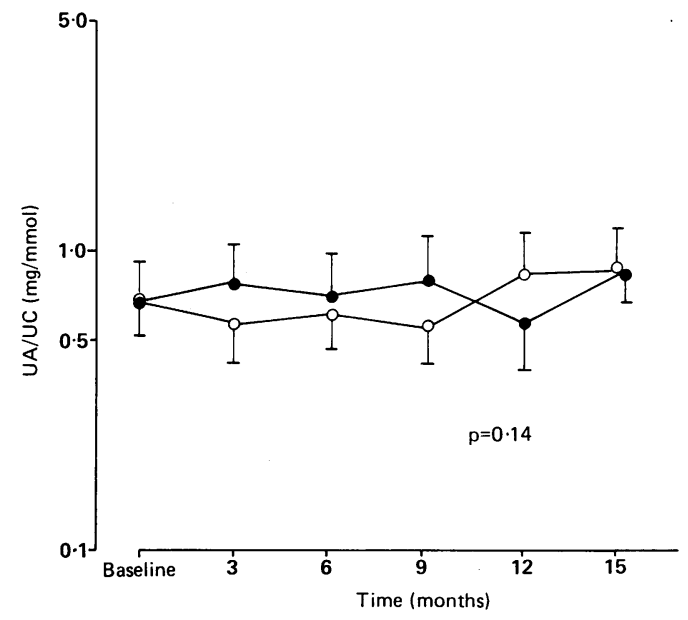

Geometric mean and $95 \%$ confidence intervals (only one shown for clarity) for $U A / U C$ in diabetic children treated with dipyridamole (-O) or placebo (O-O).

those on dipyridamole had a geometric mean ( $95 \%$ confidence interval) UA/UC of $0.60(0.42$ to 0.85$)$ compared with that of $0.87(0.62$ to $1 \cdot 21)$ in the placebo group $(p=0 \cdot 14)$. At 15 months, both groups had similar UA/UC (figure). The seven children who withdrew from the trial had UA/UC readings at the time of withdrawal that were similar to those who completed.

Seventeen children had UA/UC values above normal at screening (eight on dipyridamole and nine on placebo). Analysis indicated that those with original high UA/UC tended to maintain higher values throughout the study, but there was no evidence that the treatment worked better in this subgroup (the subgroup treatment interaction ranged from $\mathrm{p}=0.09-0.71$ for months three to 15 ).

\section{SECONDARY END POINTS}

$\mathrm{HbA}_{1 \mathrm{c}}$ and glomerular filtration rate were similar in both groups throughout the study (table 2). Thirteen children had a high glomerular filtration rate $\left(>135 \mathrm{ml} / \mathrm{min} / 1.73 \mathrm{~m}^{2}, 95 \%\right.$ tolerance level in controls) at the beginning of the study (six on dipyridamole and seven on placebo). At 12 months, glomerular filtration rate was lower in these children by $9 \%(95 \%$ confidence interval 4 to $13 \%$ ) but this difference was the same in both the dipyridamole $(9 \%$, $95 \%$ confidence interval 2 to $21 \%$ ) and the placebo treated groups $(9 \%, 95 \%$ confidence interval 2 to $15 \%$ ). Of the four withdrawals who had glomerular filtration rate measurements performed, two had high and two had normal

Table 1 Characteristics of diabetic children who completed the study and withdrawals

\begin{tabular}{|c|c|c|c|c|}
\hline & No of children & Age $^{*}$ (years) & Duration of diabetes* (years) & Sex \\
\hline $\begin{array}{l}\text { Children who completed study: } \\
\text { Dipyridamole } \\
\text { Placebo } \\
\text { All }\end{array}$ & $\begin{array}{l}25 \\
28 \\
53\end{array}$ & $\begin{array}{l}13.6(3.4) \\
11.9(3.4) \\
12.7(3.4)\end{array}$ & $\begin{array}{ll}8 \cdot 2 & (4 \cdot 7) \\
5 \cdot 6 & (3 \cdot 3) \\
6 \cdot 8 & (4 \cdot 2)\end{array}$ & $\begin{array}{l}14 M, 11 F \\
11 M, 17 F \\
25 M, 28 F\end{array}$ \\
\hline $\begin{array}{l}\text { Withdrawals: } \\
\text { Dipyridamole } \\
\text { Placebo }\end{array}$ & $\begin{array}{l}4 \\
3\end{array}$ & $\begin{array}{l}14,15,16,18 \\
12,16,18\end{array}$ & $\begin{array}{l}2,6,10,16 \\
7,8,9\end{array}$ & $\begin{array}{l}1 M, 3 F \\
1 M, 2 F\end{array}$ \\
\hline
\end{tabular}

${ }^{*}$ For children who completed the study the results are mean (SD). 
glomerular filtration rate values at baseline. One child had a glomerular filtration rate of $60 \mathrm{ml} /$ $\mathrm{min} / 1.73 \mathrm{~m}^{2}$ at $12 \mathrm{months}$, having had a glomerular filtration rate of $145 \mathrm{ml} / \mathrm{min} / 1.73 \mathrm{~m}^{2}$ at baseline. Her diabetic control was very poor throughout the trial $\left(\mathrm{HbA}_{\mathrm{lc}}\right.$ 17-18.8\%) and she developed oedema, hepatomegaly, microalbuminuria, and a high URBP/UC between nine and 12 months while taking dipyridamole. As on the residual plot the 12 month glomerular filtration rate value was clearly an outlier, she was omitted from the 12 month analysis for this variable alone.

There was no evidence of a treatment effect on blood pressure, renal size, tubular proteins, or platelet aggregation (table 2). At three months the mean ( $95 \%$ confidence interval) percentage fall in platelet count in response to platelet activating factor at 15 seconds was similar in the dipyridamole treated children, $42.5 \%(34 \cdot 7$ to $50 \cdot 3)$, compared with the children receiving placebo, $39 \cdot 3 \%(31 \cdot 3$ to $47 \cdot 3)$.

\section{CHILDREN WITH HIGH UA/UC}

Twenty four children (13 on dipyridamole and 11 on placebo) had at least one value above normal during the course of the study; three children (two on dipyridamole and one on placebo) progressed from normal UA/UC to high UA/UC, defined as at least three consecutive UA/UC $>1.17 \mathrm{mg} / \mathrm{mmol}$; and eight children (four on dipyridamole and four on placebo) had readings persistently above this level. Of these eight children with persistently high UA/UC, four had values consistently above
$2.5 \mathrm{mg} / \mathrm{mmol}$ (equivalent to a urine albumin excretion rate of $\left.20 \mu \mathrm{g} / \mathrm{min} / 1 \cdot 73 \mathrm{~m}^{2}\right)^{27}$; two were on placebo and two on dipyridamole treatment.

As no signficant treatment effects were observed during the trial, data from all 53 patients completing the trial were pooled and the associations between indices examined at baseline and at 12 months. The 11 children with high UA/UC throughout the trial had higher URBP/UC, UNAG/UC, diastolic blood pressure $\mathrm{SD}$ scores, and mean kidney length $\mathrm{SD}$ scores at both baseline and at 12 months than the rest of the children, irrespective of treatment group (table 3). Although there was a tendency for systolic blood pressure scores to be higher in the children with high UA/UC, the differences were not significant. Glomerular filtration rate was measured at baseline in only six of the 11 children with high UA/UC; values were higher than the rest of the children at baseline. At 12 months, however, one child described above had a dramatic fall in glomerular filtration rate, and the mean glomerular filtration rate in the other five children was not significantly greater than that of the remaining children.

Platelet aggregation results throughout the study were consistently above normal in only one patient. She was taking dipyridamole and had normal UA/UC and glomerular filtration rate throughout the study. If platelet aggregation in the 11 children with persistently high or progression to high UA/UC were compared with the rest of the children, although higher throughout the study, the differences were not

Table 2 Comparison of indices of renal and platelet function in children on dipyridamole compared with placebo. Results at 12 months are adjusted for age and baseline values and are expressed as mean and $95 \%$ confidence interval

\begin{tabular}{|c|c|c|c|}
\hline & \multirow[t]{2}{*}{ Baseline $(n=53)$} & \multicolumn{2}{|l|}{12 Months } \\
\hline & & Dipyridamole $(n=25)$ & Placebo $(n=28)$ \\
\hline $\begin{array}{l}\mathrm{HbA}_{\mathrm{lc}}(\%) \\
\text { Renal size (SD score) } \\
\text { URBP/UC ( } \mu \mathrm{g} / \mathrm{mmol}) \\
\text { UNAG/UC ( } \mu \mathrm{mol} \text { pnp/hr/mmol) } \\
\text { Systolic blood pressure } \\
\text { Diastolic blood pressure } \\
\text { Spontaneous platelet aggregation } \\
(\% \text { fall at } 2 \mathrm{~min})\end{array}$ & $\begin{array}{l}11 \cdot 8(11 \cdot 2 \text { to } 12 \cdot 4) \\
0.25(-0.07 \text { to }+0.57) \\
8 \cdot 2(5.9 \text { to } 11 \cdot 2) \\
38 \cdot 1(28 \cdot 2 \text { to } 50 \cdot 4) \\
110(108 \text { to } 113) \\
70(67 \text { to } 73) \\
17 \cdot 9(15.4 \text { to } 20.4)\end{array}$ & $\begin{array}{l}11 \cdot 5(10 \cdot 7 \text { to } 12 \cdot 3) \\
0 \cdot 12(-0.3 \text { to }+0 \cdot 54) \\
14 \cdot 5(9 \cdot 3 \text { to } 22 \cdot 8) \\
60 \cdot 9(46 \cdot 3 \text { to } 80 \cdot 0) \\
113(109 \text { to } 117) \\
73(69 \text { to } 77) \\
13 \cdot 5(10.6 \text { to } 16 \cdot 3)\end{array}$ & $\begin{array}{l}11 \cdot 5(10 \cdot 7 \text { to } 12 \cdot 2) \\
0 \cdot 13(-0 \cdot 31 \text { to }+0 \cdot 57) \\
10 \cdot 9(7 \cdot 2 \text { to } 16 \cdot 5) \\
63 \cdot 2(49 \cdot 2 \text { to } 81 \cdot 1) \\
112(108 \text { to } 115) \\
71(67 \text { to } 74) \\
12 \cdot 3(9 \cdot 6 \text { to } 14 \cdot 9)\end{array}$ \\
\hline & $n=36$ & $n=18$ & $n=18$ \\
\hline$\left(\mathrm{ml} / \mathrm{min} / 1 \cdot 73 \mathrm{~m}^{2}\right)$ & $129(123$ to 135$)$ & 128 (123 to 133$)$ & 124 (118 to 129$)$ \\
\hline
\end{tabular}

Table 3 Comparison of renal and platelet function in children with persistently high or progression to high UA/UC and those with normal UA/UC. Results expressed as mean (SEM) or geometric mean (95\% confidence interval) from log data.

\begin{tabular}{|c|c|c|c|c|}
\hline & & High $U A / U C(n=11)$ & Normal $U A / U C(n=42)$ & $p$ Value \\
\hline $\begin{array}{l}\text { Age (years) } \\
\text { Disease duration (years) } \\
\text { Sex } \\
\mathrm{HbA}_{\mathrm{lc}}(\%) \\
\text { Renal size (SD score) } \\
\text { URBP/UC ( } \mu \mathrm{g} / \mathrm{mmol}) \\
\text { UNAG/UC ( } \mu \mathrm{mol} \mathrm{pnp} / \mathrm{hr} / \mathrm{mmol}) \\
\text { Systolic blood pressure (SD score) } \\
\text { Diastolic blood pressure (SD score) } \\
\text { Platelet aggregation }\end{array}$ & $\begin{array}{l}\text { Baseline } \\
12 \text { Months } \\
\text { Baseline } \\
12 \text { Months } \\
\text { Baseline } \\
12 \text { Months } \\
\text { Baseline } \\
12 \text { Months } \\
\text { Baseline } \\
12 \text { Months } \\
\text { Baseline } \\
12 \text { Months } \\
\text { Baseline } \\
12 \text { Months }\end{array}$ & 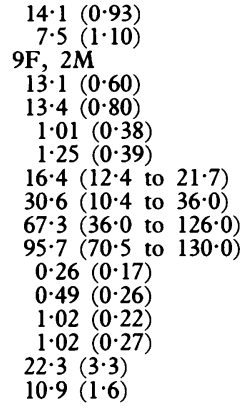 & 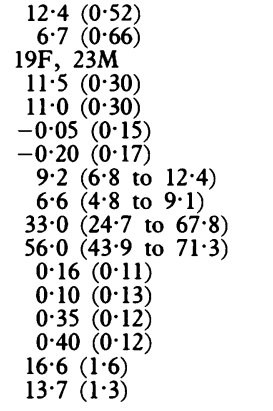 & $\begin{array}{l}0.11 \\
0.54 \\
0.07 \\
0.02 \\
0.005 \\
0.007 \\
0.0001 \\
0.002 \\
0.004 \\
0.07 \\
0.004 \\
0.62 \\
0 \cdot 16 \\
0.007 \\
0.04 \\
0 \cdot 11 \\
0.37\end{array}$ \\
\hline Glomerular filtration rate & $\begin{array}{l}\text { Baseline } \\
12 \text { Months }\end{array}$ & $\begin{array}{l}142 \cdot 7(5 \cdot 1) \\
130 \cdot 4(6 \cdot 8)\end{array}$ & $\begin{array}{l}126.3(3.4) \\
124.9(2.9)\end{array}$ & $\begin{array}{l}0 \cdot 007 \\
0.48\end{array}$ \\
\hline
\end{tabular}


significant (table 3). There was a tendency for platelet aggregation results to be lower at the end compared with the beginning of the trial in both groups and there was no evidence of dipyridamole affecting platelet aggregation.

\section{Discussion}

In this study we observed no effect of dipyridamole on urine albumin excretion in children and adolescents with IDDM, irrespective of whether urine albumin excretion at the start of the study was normal or high. In addition there were no appreciable changes in glomerular filtration rate, blood pressure, or tubular proteins in the treatment group compared with those taking placebo. The treatment and placebo groups were well matched for degree of metabolic control, and age was controlled for in the analysis.

The effects of dipyridamole on renal function are not understood; experimentally it has been reported to decrease the filtration fraction and cause efferent vasodilatation, ${ }^{21}$ possibly mediated via intrarenal adenosine. ${ }^{22}$ This could result in a decrease in proteinuria, which may be independent of an antiplatelet action. ${ }^{32}$ Dipyridamole has been reported to reduce proteinuria in a variety of both childhood and adult renal disease, but these studies were uncontrolled. ${ }^{16}{ }^{33}$ In a placebo controlled study of antiplatelet treatment in membranoproliferative glomerulonephritis, dipyridamole in combination with aspirin stabilised the glomerular filtration rate but interestingly, had no effect on proteinuria. ${ }^{15}$ In diabetic nephropathy most studies have been undertaken on adults with established nephropathy and in all, dipyridamole was taken in combination with aspirin. Thus Hopper et al reported a decrease in proteinuria but also a decrease in creatinine clearance in 16 adults with established diabetic nephropathy; the study had a crossover design and patients took the active drugs for a period of six weeks. $^{17}$ Christopher et al reported a decrease in albumin excretion and stabilisation in glomerular filtration rate over a two year period in seven adults with established diabetic nephropathy compared with six who took placebo. ${ }^{18}$ Most recently, Donadio and colleagues reported the results of treatment with aspirin and dipyridamole for $4 \cdot 3$ years on urine albumin excretion, glomerular filtration rate, and platelet survival in 28 diabetic adults with established nephropathy. ${ }^{20}$ They reported that seven of the 28 patients had a decrease in urine albumin excretion and stabilisation of renal function, with decline in glomerular filtration rate occurring at the rate of $6 \mathrm{ml} / \mathrm{min} /$ year in this group. It is unclear, however, how these seven patients were selected for separate analysis, which appears to have been undertaken retrospectively rather than prospectively. In addition, the study was uncontrolled and although not significant, basal rates of urine albumin excretion were lower and glomerular filtration rate was higher in patients who 'responded'. Platelet survival improved and urinary thromboxane $\beta_{2}$ excretion decreased on treatment, but not necessarily in those patients who had a more stable renal course. In a subgroup of patients treated at the beginning of the study with dipyridamole alone, the decrease in thromboxane $\beta_{2}$ over a four week period was not significant. The conclusion that a combination of aspirin and dipyridamole reduces urine albumin excretion and stabilises renal function in diabetic nephropathy still requires confirmation.

In the only other study to investigate the effect of dipyridamole on renal function earlier in diabetes, the drug was again taken in combination with aspirin. Hopper et al measured the effect of a combination of aspirin and dipyridamole on exercise induced albuminuria in adults early in the disease. ${ }^{34}$ Only six patients were studied, however, and albumin excretion rates in the treated group were significantly reduced only when expressed as ratios of results collected after exercise to those collected immediately before exercise.

The role of platelets in the pathogenesis of diabetic nephropathy is unclear. Whereas there are reports of increased platelet activation in the presence of established microvascular complications, ${ }^{4-6}$ the role of platelets in the pathogenesis of complications is much less secure. Two recent studies using sensitive techniques failed to show any abnormalities in platelet aggregation, or excretion of urinary metabolites of thromboxane synthesis in diabetic adults without evidence of microvascular complications. ${ }^{9} 10$ Hendra et al observed no differences in platelet aggregation in platelet rich plasma or whole blood diabetic adults with short disease duration. ${ }^{10}$ Platelet aggregation in whole blood has the advantage of not requiring centrifugation, which may result in loss of the more active platelets as well as removing red and white cells which can liberate platelet active substances. ${ }^{30} 35$ Indeed, strong circumstantial evidence suggests that 'spontaneous' platelet aggregation in stirred whole blood is a reflection of the aggregating effect of adenosine diphosphate released by erythrocytes by mechanical stirring. ${ }^{35}$ Dipyridamole, which requires high concentrations to inhibit platelet aggregation in platelet rich plasma, ${ }^{36} 37$ has been found to inhibit both spontaneous aggregation and aggregation in response to platelet activating factor in whole blood in vitro. ${ }^{38-40}$ In this study, however, we were unable to detect any differences in either spontaneous or platelet activating factor induced aggregation in diabetic children taking dipyridamole compared with those on placebo treatment. The children had taken their morning dipyridamole three to six hours before having blood taken and it may be that blood concentrations were no longer in the therapeutic range. Mahony et al, however, have suggested that because of the enterohepatic circulation, there is no need for dipyridamole to be taken more frequently than twice daily. ${ }^{41}$ The other possible explanation is that the aggregation experiments were performed too long after venepuncture. Saniabadi et $a l$, using a rolling rather than stirring model to induce 'spontaneous' aggregation, observed significant inhibition by dipyridamole only if the aggregation was initiated within three minutes after venepuncture. $^{31}$ 
In this study there were a total of 11 children who either had persistently high UA/UC or progressed to high UA/UC. Four of these children had UA/UC equivalent to $>20 \mu \mathrm{g} / \mathrm{min} /$ $1.73 \mathrm{~m}^{2}$ throughout the study (two on placebo and two on dipyridamole treatment): a value which has been the consensus definition of microalbuminuria. In comparison with the remaining 42 children, the 11 children with high UA/UC had higher $\mathrm{HbA}_{1 \mathrm{c}}$, bigger kidneys, higher 'tubular' protein excretion rates, and higher diastolic blood pressure both at baseline and 12 months later; the values in the four children with highest UA/UC were even higher for all these parameters. The results for glomerular filtration rate are difficult to interpret because only six of the 11 had this measured; although values were higher in children with high UA/ UC at baseline, the difference was not significant at 12 months.

In conclusion, we have shown that dipyridamole taken over a 12 month period has no significant effect on urine albumin excretion, 'tubular' protein excretion, glomerular filtration rate, blood pressure, or platelet aggregation in whole blood in children with IDDM. Children with levels of urine albumin excretion above the normal range also have consistently higher $\mathrm{HbA}_{1 \mathrm{c}}$, increased tubular protein excretion, larger kidneys, and higher diastolic blood pressure, but no consistent increase in platelet aggregation. Much longer follow up is required to observe whether the values of UA/UC above the normal range but less than $20 \mu \mathrm{g} / \mathrm{min} / 1.73 \mathrm{~m}^{2}$ are predictive for nephropathy, and whether other indices of renal function may contribute to the identification of patients at risk of nephropathy.

We thank Dr M Savage for permitting the diabetic children at Queen Elizabeth Hospital in Hackney to participate in the study, Queen Elizabeth Hospital in Hackney to participate in the study, Mrs Vanita Shah for measuring urinary albumin, Dr
P Tomlinson and Dr N Dalton from United Medical and Dental P Tomlinson and Dr N Dalton from United Medical and Dental
Schools of Guys and St Thomas's Hospitals, London for measuring urinary retinol binding protein and N-acetyl- $\beta$-Ding urinary retinol binding protein and $\mathrm{N}$-acetyl- $\beta$ - $\mathrm{D}$ glucosaminidase, $\mathrm{Mr} \mathrm{W}$ Wilson for measuring urinary creatinine concentrations and Ms Carol Smith for her help with the platelet
and serotonin studies. We also thank Dr R Tomiak for assistance

with planning and running the trial

This project was supported by grants from Boehringer Ingelheim and the Kidney Research Aid Fund.

1 Mustard JF, Packham MA. Platelets and diabetes mellitus. $N$ Engl f Med 1977;297:1345-7.

2 Mustard JF, Packham MA. Editorial retrospective: platelets and diabetes mellitus. $N$ Engl f Med 1984;311:665-7.

3 Nath KA. Platelets, antiplatelet therapy and diabetic nephropathy. Mayo Clin Proc 1988;63:80-5.

pathy. Mayo Clin Proc 1988;63:80-5.
4 Jones RL, Paradise C, Peterson CM. Platelet survival in patients with diabetes mellitus. Diabetes 1981;30:486-9.

patients with diabetes mellitus. Diabetes 1981;30:486-9.
5 Butkus A, Skrinstka VA, Schumacher OP. Thromboxane production and platelet aggregation in diabetic subjects $211-23$

6 Preston FE, Ward JD, Marcola BH, Porter NR, Timberley WR, O'Malley BC. Elevated beta-thromboglobulin levels and circulating platelet aggregates in diabetic microangiopathy. Lancel 1978;i:238-40.

7 Sagel J, Colwell JA, Crook L, Laimains $M$. Increased platelet aggregation in early diabetes mellitus. Ann Int Med 1975;82:733-8

8 Dallinger KJC, Jennings PE, Toop MJ, Gyde OHB, Barnett $\mathrm{AH}$. Platelet aggregation and coagulation factors in insulin dependent diabetics with and without microangiopathy. Diabetic Medicine 1987;4:44-8.

9 Alessandrini P, McRae J, Feman S, FitzGerald A. Thromboxane biosynthesis and platelet function in type diabetes mellitus. $N$ Engl f Med 1988;319:208-12.

10 Hendra TJ, Oughton J, Smith CCT, Betteridge DJ, Yudkin JS. Platelet function in uncomplicated insulindependent diabetic patients at rest and following exercise. Diabetic Medicine 1988;5:469-73.
11 Gisinger $\mathrm{CH}$, Schernthaner G. Increased platelet malondialdehyde, but normal platelet sensitivity to adenosine-5 dehyde, but normal platelet sensitivity to adenosine-5diabetics without vascular complications. Diabetes Res 1986;3:401-5.

12 Barnett AH, Wakelin K, Leatherdale BA, et al. Specific thromboxane synthetase inhibition and albumin excretion rate in insulin-dependent diabetes. Lancet 1984;i:1322-5.

13 FitzGerald GA. Dipyridamole. $N$ Engl $\mathcal{F}$ Med 1987;316: 1247-57.

14 Antiplatelet Trialists' Collaboration. Secondary prevention of vascular disease by prolonged antiplatelet treatment. $\mathrm{Br}$ Med $\mathcal{F}$ 1988;296:320-31.

15 Donadio JV, Andersen CF, Mitchell, et al. Membranoproliferative glomerulonephritis: a prospective clinical trial of platelet-inhibitor therapy. $N$ Engl 7 Med 1984;310:1421-6.

16 Ueda N, Kawaguchi S, Niinomi Y, et al. Effect of dipyridamole treatment on proteinuria in paediatric renal disease. Nephron 1986;44:174-9.

17 Hopper AH, Tindall H, Davies JA. Aspirin/dipyridamole treatment reduces proteinuria in diabetic nephropathy. treatment reduces proteinuria
Transplant Proc 1986;28:1644.

18 Christopher TG, Samuels K. A study of aspirin and dipyridamole in diabetic glomerulosclerosis. Xth International mole in diabetic glomerulosclerosis. Xth International

19 Makino H, Okada S, Ota Z. Effect of dipyridamole on proteinuria of diabetic nephropathy. Clin Nephrol 1983;20. 160

20 Donadio JV, Ilstrup DM, Holley KE, Romero JC. Platele inhibitor treatment of diabetic nephropathy: a 10 -year prospective study. Mayo Clin Proc 1988;63:3-16.

21 Dejong PE, van der Meer J, van der Hem GK. The antiproteinuric effect of dipyridamole is the consequence of an efferent vasodilatation. Kidney Int 1986;29:184.

22 Arend LJ, Thompson CI, Speilman WS. Dipyridamole decreases glomerular filtration in sodium-depleted dog: evidence for mediation by intrarenal adenosine. Circ Res 1985;56:242-51.

23 Gibb DM, Dunger D, Levin $M$, Shah V, Smith $C$ Barratt TM. Early markers of the renal complications of insulin-dependent diabetes mellitus in children. Arch Dis Child 1989;64:984-91

24 Topping MD, Forster HW, Dolman C, Luczynska CM Bernard AM. Measurement of urinary retinol-binding protein by enzyme-linked immunosorbent assay and its application to the detection of tubular proteinuria. Clin application to the detect

25 Marulin D. Rapid colorimetric assay of $\beta$-D-galactosidase and $\mathrm{N}$-acetyl- $\beta$-D-glucosaminidase in human urine. Clin Chim Acta 1976;73:453-6

26 Gibb DM, Tomlinson PA, Dalton NR, Turner C, Shah V, Barratt TM. Renal tubular proteinuria and microalbumin uria in diabetic patients. Arch Dis Child 1989;64:129-34.

27 Gibb DM, Shah V, Wilson W, Preece M, Barratt TM. Variability of urine albumin excretion in normal and diabetic children Pediatric Nephrology 1989;3:414-9.

28 Dinkel E, Ertel M, Dittrich M, Peters H, Berres M, SchulteWissermann H. Kidney size in childhood. Sonographical growth charts for kidney length and volume. Pediatr Radiol 1985;15: $38-43$.

29 National Heart, Lung and Blood Institute, Bethesda Maryland. Report of the second task force on blood Maryland. Report of the second task force on blood pressure $1-25$.

30 Fox SC, Burgess-Wilson M, Heptinstall S, Mitchell JRA. Platelet aggregation in whole blood determined using the Ultra-Flo 100 Platelet Counter. Thiomb Haemost 1982;48: $327-9$

31 Saniabadi AR, Lowe GDO, Forbes CD. Effect of dipyridamole on spontaneous platelet aggregation in whole blood decreases with time after venepuncture: evidence for the role of ADP. Thromb Haemostas 1987;58:744-8.

32 Ogawa S, Naruse T. Effects of various antiplatelet drugs and a defibrinating agent on experimental glomerulonephritis in rats. Clin Lab Med 1982;99:428-41.

33 Ishikawa $\mathrm{H}$, Honjo A, Hayashi $\mathrm{M}$, et al. Effects of dipyridamole on proteinuria in chronic glomerulonephritis and the neph

34 Hopper AH, Tindall H, Urquhart S, Davies JA. Reduction of exercise-induced albuminuria by aspirin-dipyridamole in patients with diabetes mellitus. Horm Metab Res 1987;19. pati-3.

35 Saniabadi AR, Lowe GDO, Barbenel JC, Forbes CD. Further studies on the role of red blood cells in spontaneous platelet aggregation. Thromb Res 1985;38:225-32.

36 Weiss HL. Dipyridamole and other phophodiesterase inhibitors. In: Weiss HJ, ed. Platelets, pathophysiology and antiplatelet drug therapy. New York: Alan R Liss, 1982:57-62.

37 Harker LA. Mechanisms of action of dipyridamole. Thromb Res 1983;suppl IV:39-46.

38 Gresele P, Zoja C, Deckmyn H, Armout J, Vermylen J, Verstraete $M$. Dipyridamole inhibits platelet aggregation in whole blood. Thromb Haemostas 1983;50:852-6.

39 Harrison MGJ, Pollock SS, Steiner M, Weisblatt E. Inhibitors of spontaneous platelet aggregation in whole blood Atherosclerosis 1985;58:199-203.

40 Heptanstall S, Fox S, Crawford J, Hawkins M. Inhibition of platelet aggregation in whole blood by dipyridamole and aspirin. Thromb Res 1986;42:215-23.

41 Mahony C, Wolfram KM, Cocchetto DM, Bjornsson TD. Dipyridamole kinetics. Clin Pharmacol Ther 1982;31: 330-8. 